Research, part of a Special Feature on Compensation and Reward for Environmental Services in the Tropics

\title{
Compensation and Rewards for Environmental Services in the Developing World: Framing Pan-Tropical Analysis and Comparison
}

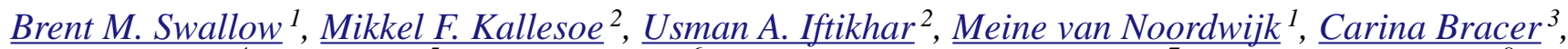 \\ $\underline{\text { Sara J. Scherr }}^{4},{ }_{\text {K. V. Raju }}{ }^{5}$, Susan V. Poats $^{6}$, Anantha Kumar Duraiappah ${ }^{7}$, Benson O. Ochieng ${ }^{8}$, \\ Hein Mallee $^{9}$, and Rachael Rumley ${ }^{1}$
}

\begin{abstract}
This is the first of a series of papers that review the state of knowledge and practice regarding compensation and rewards for environmental services in the developing world. The paper begins with an assessment of the historical development of compensation and reward mechanisms within a broader context of changing approaches to nature conservation and environmental policy. The assessment shows that greater interest in compensation and reward mechanisms has emerged within a policy context of changing approaches to nature conservation and flexible multi-stakeholder approaches to environmental management. In the developing world, an even greater variety of perspectives has emerged on the opportunities and threats for using compensation and rewards for environmental services. Within that background, the paper clarifies key concepts - including the distinction between compensation and reward - and presents a conceptual framework for typifying and characterizing different types of mechanisms that link ecosystem stewards, ecosystem service beneficiaries, and intermediaries.
\end{abstract}

Key Words: Africa; Asia; compensation; ecosystems service; Latin America; payment for environmental service; rewards

\section{INTRODUCTION}

Ecosystems are crucially important to human societies for the many and varied ecosystem services upon which life is based. Ecosystems provide products of direct value to people-food, fiber, and fuel-and an array of indirect benefits, including water filtration, climate regulation, nutrient cycling, pollination, pest control, and disease regulation. Healthy ecosystems are particularly important to the rural poor of the developing world, people who often live in very close connection to their natural surroundings. Despite the fundamental importance of ecosystem services to human well-being, however, ecosystems and their constituent goods and services continue to decline at alarming rates (Millenium Ecosystem Assessment 2005).

A major reason for the systemic decline of ecosystems is that many ecosystem services are not priced or assigned value by the prevailing systems of production, exchange, and regulation. Although there are markets for many of the "provisioning" ecosystem services, there tend to be incomplete or missing markets for the "regulating," "supporting," and "cultural" services. Reasons for market failure are well known: cultural services tend to have public good characteristics (non-rivalry in consumption and non-excludability), whereas regulatory services are highly influenced by production externalities.

Societies have devised a number of public policy instruments to cope with these market failures. Some instruments, particularly regulations, property rights, and financial instruments, have been used for environmental governance for many years. Regulatory instruments tend to be implemented in a top-down and rigid manner, earning them the name "hard policy instruments" or "command-andcontrol" instruments. Over the last 20 to 30 years, a variety of new "soft" environmental policy 
instruments have been devised and implemented. Soft policy instruments tend to be more flexible and subject to negotiation and multi-stakeholder dialog, and consistent with market approaches to efficiency.

There are optimistic and pessimistic views of these recent attempts to harness market forces for the dual goals of improved ecosystem management and enhanced human well-being. Overall, one might conceive of four extreme circumstances of tradeoffs or complementarities between environmental conservation and human well-being: (1) ecosystems may be conserved and the poor made better off; (2) ecosystems may be conserved at the expense of the poor who rely on the ecosystem services; (3) the poor may be made better off, but at the expense of ecosystem services that are highly valued by the larger society; or (4) ecosystems may continue to degrade at the same time as the rights and well-being of the poor decline. Which of these scenarios is likely to hold, and under what conditions, were key questions addressed in a pan-tropical scoping study of compensation and reward for environmental services conducted in 2006 and 2007. This introductory paper reviews the key concepts and perspectives that were used to frame that pantropical review.

\section{EVOLUTION OF CONSERVATION APPROACHES}

An early conservation approach called the wilderness conservation approach, became the backbone of the western conservation movement in the 20th century. This approach focused on isolating and protecting designated areas and species from surrounding areas of human impact, based on the assumption that growth of human populations and economic activity is inevitably destructive to the environment (Callicott 1991). The wilderness conservation approach underpinned the creation of the National Parks system in the United States, which continues to inspire the parks approach to conservation across the world. Park creation involved the removal of people from parks and their resettlement outside of park boundaries. Access to the park was largely restricted to local community members, managed by a system of "fences and fines." The parks approach continues to be the main approach to conservation across the world (Chape et al. 2003).
Integrated conservation and development projects (ICDPs) emerged as a complement to the wilderness conservation approach in the 1980s. These ICDPs were designed to simultaneously advance: (1) more effective biodiversity conservation in parks and surrounding landscapes, (2) increased community participation in conservation and development, and (3) economic opportunities for the rural poor (Wells et al. 1999). However, it is generally acknowledged that the impacts of ICDPs on conservation and economic development have been mixed (Oates 1999). On the whole, the schemes have often been difficult to sustain in financial terms, and their conservation impacts have rarely matched expectations.

The concept of using direct payments for biodiversity conservation has emerged in the last 10 years as the limitations of the parks and ICDP approaches have become clear. Payment for environmental services explicitly recognizes the legitimate right of people to live in conservation landscapes, providing direct payments to those people whose actions are consistent with agreed biodiversity conservation or watershed management plans (Ferraro and Kiss 2002).

\section{ORIGINS AND DEVELOPMENT OF MARKET INSTRUMENTS FOR ENVIRONMENTAL POLICY}

The theory behind incentive or market-based approaches to environmental policy was first developed by economists in the 1960s. Crocker (1966) proposed cap-and-trade systems to manage pollution: limited amounts of tradable rights to pollute or use natural resources would be distributed to stakeholders, with firms with lower pollutionabatement costs able to sell emission permits to firms with higher costs. Compared with the use of fixed standards, these flexible mechanisms would meet the same emission standards at lower total cost to the economy (Woodward 2005).

In 1977, the U.S. Environmental Protection Agency began an emission-offset scheme that allowed firms to trade and bank credits for emissions of carbon dioxide $\left(\mathrm{CO}_{2}\right)$, sulfur dioxide $\left(\mathrm{SO}_{2}\right)$, and nitrous oxides $\left(\mathrm{NO}_{\mathrm{x}}\right)$. The largest and perhaps most successful emission-trading regimes in the United States were the lead trading regime for reducing lead content of gasoline and the $\mathrm{SO}_{2}$ allowance trading regime for acid rain control (Stavins 2002). 
Since 1992, there has been considerable experimentation with flexible policy instruments in Europe. Jordan et al. (2005) describe four types of new environmental policy instruments that have emerged over the last 15 years: (1) market-based instruments, including eco-taxes, tradable permit systems, subsidies, and deposit-refund schemes, (2) eco-labels, (3) voluntary environmental management and business certification systems, and (4) voluntary agreements between industry and public authorities, including negotiated agreements, public voluntary schemes, and unilateral commitments.

Di Leva (2002) describes three categories of market-based instruments that have made significant inroads in developing countries since the Rio Summit of 1992: (1) revenue-raising measures adjusted to environmental concerns, including ecotourism, (2) real property measures adjusted to conservation needs, such as conservation easements, and (3) protection through a variety of more recent legal instruments, such as carbon sequestration under the Kyoto Protocol and transferable quotas. In addition, there has been a limited number of self-organized deals in which the beneficiaries of environmental services make direct payments to ecosystem stewards for the maintenance or restoration of environmental services. Overall, environmental policy in the developing world still relies primarily on hard policy instruments, most of which extend from colonial policy approaches (e.g., Fay and Michon 2005).

\section{CONTRASTING PERSPECTIVES ON COMPENSATION AND REWARD FOR ENVIRONMENTAL SERVICES}

The previous sections of the paper support the view that conservation and environmental policy perspectives are the main paradigms promoting compensation and rewards for environmental services across the globe. At least within the developing world, however, it appears that there are several other perspectives that are as important and prevalent. The following paragraphs present our characterization of these different perceptions. We draw special attention to cases that were presented at the regional workshops.

\section{Wildlife Conservation Perspective}

Compensation and reward for environmental services (CRES) mechanisms are mostly viewed as a source of conservation finance that may or may not complement or replace public funding and entry fees. Compensation mechanisms, such as the consolation mechanism instituted around Nairobi Park in Kenya, are used to compensate farmers for damage to livestock and crops caused by wildlife. Reward mechanisms, such as the wildlife lease program also operating around Nairobi Park, may provide landowners with additional incentive to maintain wildlife corridors (see Ochieng et al. 2007). Among the wildlife conservation community, there continues to be significant skepticism about the potential for CRES mechanisms to provide wildlife conservation, especially mechanisms such as the Clean Development Mechanism that may result in trading water and biodiversity for carbon.

\section{Environmental Management Perspective}

A CRES mechanism may be mostly viewed as a way to provide positive incentives for good environmental stewardship to go along with the standard set of environmental regulations. As discussed in the literature review above, the movement toward CRES in the developing world is part of a more general global trend toward negotiation and softer environmental regulation. Many of the participants in the regional workshops expressed interest in CRES mechanisms for resolving conflicts over resource access and benefit sharing.

\section{Poverty Reduction Perspective}

A CRES mechanism may be mostly viewed as a possible alternative income stream for poor people, that is, a new way to "put money in farmers' pockets." This emerged as a dominant perspective at the African regional workshop. At the Latin America and Asia regional workshops, on the other hand, many participants expressed concerns that CRES mechanisms, particularly carbon finance mechanisms, might also dispossess indigenous and poor people. This perspective has been strongly expressed in media reports of carbon sequestration projects in Uganda and in statements by indigenous people's groups in Latin America (see Poats 2007). Indeed the Rewarding Upland Poor for 
Environmental Services (RUPES) project in Southeast Asia was expressly designed to explore the potential for pro-poor mechanisms (http://www. worldagroforestrycentre.org/sea/Networks/RUPES/ index.asp).

\section{Economic Planning Perspective}

A CRES mechanism may be regarded as a flexible and efficient way of correcting market failures and collective action problems. The papers by Ferraro and Kiss (2002) and Pagiola et al. (2002, 2004) express this perspective.

\section{Rural Empowerment and Social Justice Perspective}

A CRES mechanism may be viewed as a way to redress historical imbalances in the power, rights, and responsibilities of resource-dependent people vis-à-vis ecosystem-service beneficiaries who often enjoy greater influence over the political and economic processes. McKay and Bjornlund (2001) have explicitly considered water markets in Australia from the social justice perspective.

\section{Business Perspectives}

There appear to be multiple business perspectives on CRES: (1) redressing environmental damage caused by business operations as a legal or ethical imperative, (2) a component of a corporate social responsibility strategy designed to maintain or enhance the reputation of the business, (3) complying with current or likely future environmental regulations, or (4) sustaining or improving crucial ecosystem services that are inputs into business operations. A joint publication of the Earthwatch Institute, International Union for Conservation of Nature (IUCN), World Business Council for Sustainable Development (WBCSD), and World Resources Institute (WRI) (Earthwatch Institute et al. 2006) summarizes information on these multiple motivations of business. Compliance with current environmental regulations-particularly in the European Union Emission Trading Scheme -is the major factor driving the interests of European businesses in the carbon trade. Compliance with likely future environmental regulations is driving U.S. business interests in the voluntary carbon market (Hamilton et al. 2007).

\section{Farmers and Ecosystem Stewards}

The people who live within key ecosystems may also see CRES from several perspectives: (1) official recognition of their rights to reside in, use, and modify a protected ecosystem, (2) a new government program that provides public services in exchange for formation of groups or planting trees, (3) a new source of revenue for performing a defined service, or (4) a new way for governments and powerful interest groups to dispossess people from their land. The World Agroforestry Centre (ICRAF) and Lampung University recently conducted an analysis of farmers' preferences for the elements of conditional social forestry contracts in Sumatra and found that farmers place greatest weight on recognition of their rights and public services that they relate with the social forestry contracts (Arifin et al. 2008).

\section{Environmental Service Beneficiaries Seeking Redress}

Environmental service beneficiaries seeking redress for environmental damage caused by others may see compensation for environmental services as one of several ways to redress past grievances. Voluntary compensation payments, negotiated outside of the legal system, may prove to be more effective than legally enforced payments.

\section{A CONCEPTUAL MODEL OF COMPENSATION AND REWARD FOR ENVIRONMENTAL SERVICES}

\section{Definitions and Concepts}

A variety of terms are used in the academic and empirical literature to describe new market instruments for environmental policy. This section seeks to clarify some of these key terms, structured around a simple conceptual framework.

Two important concepts are environmental services and ecosystem services. In this paper, we follow the environmental economics concept of "environmental service" as a positive benefit that people obtain from the environment. The environmental services of forests and landscapes, for example, are usually categorized into watershed protection, biodiversity conservation, atmospheric regulation (including greenhouse gas mitigation), and landscape beauty (e.g., Pagiola et al. 2002). 
We also follow the definition of "ecosystem service" used by the Millenium Ecosystem Assessment (MA) "....the benefits people obtain from ecosystems. These include provisioning services such as food and water, regulating services such as regulation of floods, drought, land degradation, and disease, supporting services such as soil formation and nutrient cycling, and cultural services such as recreational, spiritual, religious and other nonmaterial benefit" (MA 2005:27).

In practice, the main difference between ecosystem services and environmental services is the inclusion or exclusion of provisioning ecosystem services. Most provisioning ecosystem services - food, fiber, timber - are excludable and non-competitive goods for which markets develop most readily. The focus in this paper is on environmental services, most of which are regulating, supporting, and cultural services of ecosystems - for which markets do not easily develop.

Payment for environmental service (PES) is another key concept. In a 2005 publication, Sven Wunder proposed the following definition for PES: “....a voluntary, conditional transaction where at least one buyer pays at least one seller for maintaining or adopting sustainable land management practices that favour the provision of a well-defined environmental service" (Wunder 2005:3). Although this definition has been generally accepted by economists working on market-based instruments for environmental policy, it suffers from being too restrictive. For example, Robertson and Wunder (2005) have shown that the conditionality requirement rules out most incentive-based instruments in use in developing countries, using terms like "PES-like" and "incipient PES" as more inclusive terms. Rosa et al. (2004) are among the group of analysts who favor the term "compensation for environmental services," although as a legal concept compensation refers to "...financial compensation recoverable by reason of another's breach of duty" (Wikimedia Foundation 2009).

Here, we accept the Wunder (2005) definition of payment for environmental service and provide additional concepts to better describe the range of mechanisms that are being negotiated for managing interactions between people with diverse interests in ecosystem management and environmental services. Building on the work of Tomich et al. (2004), we present here a conceptual framework that illustrates different types of relationships among stewards, beneficiaries, and intermediaries.

\section{Identification and Characterization of Actors in Compensation and Rewards for Environmental Services}

There are three generic types of stakeholders or functional groups in compensation and rewards for environmental services: ecosystem stewards, environmental service beneficiaries, and intermediaries.

An "ecosystem steward" is an entity (individual, family, group, community) whose actions modify the quantity or quality of ecosystem services available to environmental service beneficiaries. Ecosystem stewards are recognized by society as having the right to interact with an ecosystem, provided they accept limitations on those rights and obligations to maintain the ecosystem. Experience shows that there are several defining characteristics of ecosystem stewards and their relationships with ecosystems and other actors:

1. Exclusion or inclusion criteria. What criteria define who is in and out of different groups of ecosystem stewards? Is inclusion or exclusion based on ethnicity, gender, ability to pay, residential location, or political power?

2. Type and strength of social organization among ecosystem stewards, including their social and political capital.

3. Nature of the cause-effect relationships between ecosystem stewards and the ecosystem. What technologies, land-use practices or enterprises are associated with benign or destructive use of the ecosystem? What components or locations in the ecosystem are particularly important for ecosystem structure and function? How fast or slow are the relationships-do they act over minutes, days, or decades? Are the relationships relatively linear, non-linear, or subject to thresholds?

4. Location vis-à-vis the ecosystem. Are they upstream, midstream, or downstream within a watershed, adjacent to or more distant from a protected area, located within or outside of an ecosystem?

5. Rights and discretion over the way the ecosystem is used and managed. 
6. Level of well-being or type of poverty, both in absolute terms and relative to other actors affecting the ecosystem.

7. Demographic composition-in terms of gender, ethnicity, age, and livelihood strategies.

"Environmental service beneficiaries" are entities (individuals, families, groups, corporations, towns, utility companies) who benefit from the environmental services generated by an ecosystem. Environmental service beneficiaries can be characterized by:

1. Types of environmental service they benefit from.

2. Location-physical location within or outside of the ecosystem, within or outside of the administrative area or country where the ecosystem is located.

3. Degree and type of dependence on the environmental service-for subsistence or commercial exploitation.

4. Access to alternative supplies of the environmental services or good substitutes for those services.

5. Level and trend in different dimensions of human well-being or deprivation.

6. Strength and type of property rights or entitlements to the environmental service.

7. Demographic composition-gender, ethnicity, age, and occupation.

8. Type and strength of groups and other forms of social organization.

9. Their action resources with regard to the environmental services and their relations with others (see Ostrom (2005) for a description of action resources).

"Intermediaries" are entities that directly or indirectly shape interactions among ecosystem stewards, environmental service beneficiaries, and the ecosystem itself. Environmental service intermediaries perform a variety of roles in compensation and rewards for environmental services, including providing information relevant to design, monitoring, and evaluation of contracts and negotiated agreements, providing a forum for negotiations, enforcing the terms of regulations and contracts, and offsetting the transaction costs of establishing and maintaining a working mechanism. Intermediaries can be characterized by:

1. Mandate, objectives and perspectivesintermediaries vary greatly in terms of mandate and objectives, from international conservation organizations, international and national research organizations, local governments, philanthropists, international development assistance organizations, state and local arms of government.

2. Representation-some intermediaries act on behalf of ecosystem stewards, environmental service beneficiaries, or third parties with interest in the ecosystem or people living in the ecosystem.

3. Source of authority-international convention, national law or policy, customary laws, local practice, control over financial or physical resources, ownership or direct financial interest in resource use, influence over the behavior of other authorities.

4. Type of influence on the behavior of ecosystem service modifiers and environmental service beneficiaries-imposition or enforcement of regulations on resource use; subsidization of the costs of establishing or maintaining an environmental management regime; subsidization or provision of positive incentives.

\section{Definition and Typology of Compensation and Rewards for Environmental Services}

We define CRES as follows: "contractual arrangements and negotiated agreements among ecosystem stewards, environmental service beneficiaries, or intermediaries, for the purpose of enhancing, maintaining, reallocating or offsetting damage to environmental services." 
A particular CRES contract or negotiated agreement will include a compensation or reward instrument or combination of instruments. Thus, we need to define the following terms:

"Compensation for Environmental Services" (CES) are payments or other forms of restitution made to environmental service beneficiaries or ecosystem stewards to offset foregone entitlements to environmental services or ecosystem stewardship benefits. There are two types of CES, here labeled as CES1 and CES2.

- CES1-Compensation to environmental service beneficiaries for socially disappointing damage to ecosystem services by ecosystem stewards. This includes self-organized deals between stewards and beneficiaries, restitution payments ordered by intermediary organizations, and compensation payments made by intermediary organizations.

- CES2-Self-organized contracts, negotiated agreements or tradable allowance and permit systems that facilitate exchange of environmental service entitlements among environmental service beneficiaries. This includes cap-and-trade systems for emissions and conservation concessions.

"Rewards for Environmental Services" (RES) are inducements provided to ecosystem stewards to give them incentive to enhance or maintain environmental services. Again, there are two types of RES: RES1 and RES2.

- RES1-Rewards to ecosystem stewards for foregone stewardship rights or reduction of threats. This includes self-organized deals between ecosystem stewards and environmental service beneficiaries, public programs of reward made on behalf of beneficiaries and ecolabeling and certification schemes for products generated through good stewardship practices.

- RES2- Rewards to ecosystem stewards for undertaking extra investments or management practices that restore or enhance the ecosystem. This includes self-organized deals and public programs of reward.
Figure 1 presents these concepts in graphical form. The upper-left bubbles represent the ecosystem, with ecosystem structure and function transformed by an ecological production function into ecosystem services. Environmental service beneficiaries benefit from environmental services, either directly or through some value or market chain. Ecosystem stewards interact directly with the ecosystem, with three types of effects: use or extraction of ecosystem services, conservation and protection of the ecosystem, and investment and management to enhance or restore the ecosystem. The solid lines joining the boxes show direct relationships. The four types of compensation and rewards for environmental services are indicated, with dashed lines showing transfers of resources.

Experience shows that mechanisms of compensation and rewards for environmental services can be characterized in several respects in addition to the stakeholder characteristics discussed above. These characteristics affect the performance of the mechanism in terms of ecosystem management and impacts on poverty and human well-being.

1. Relationships among ecosystem stewards, environmental service beneficiaries, and intermediaries. What is the nature of previous and confounding relations between ecosystem stewards, environmental service beneficiaries, and intermediaries? Is the mechanism the only contractual or negotiated relationship among the parties, or is this part of a multistranded social, economic, or political relationship?

2. Characteristics of the mechanisms:

- Nature of the contract or agreement. Are there individual or group contracts? What type of enforcement mechanism is in place?

- Transaction costs of establishing and operating the mechanism, including information, contracting and enforcement, and the distribution of those transaction costs;

- Type of remuneration or incentives provided as compensation or reward. Is there quid pro quo exchange of money for divisible, excludable goods, as is normally the case for 
Fig. 1. Characterization of mechanisms for compensation and reward for environmental services.

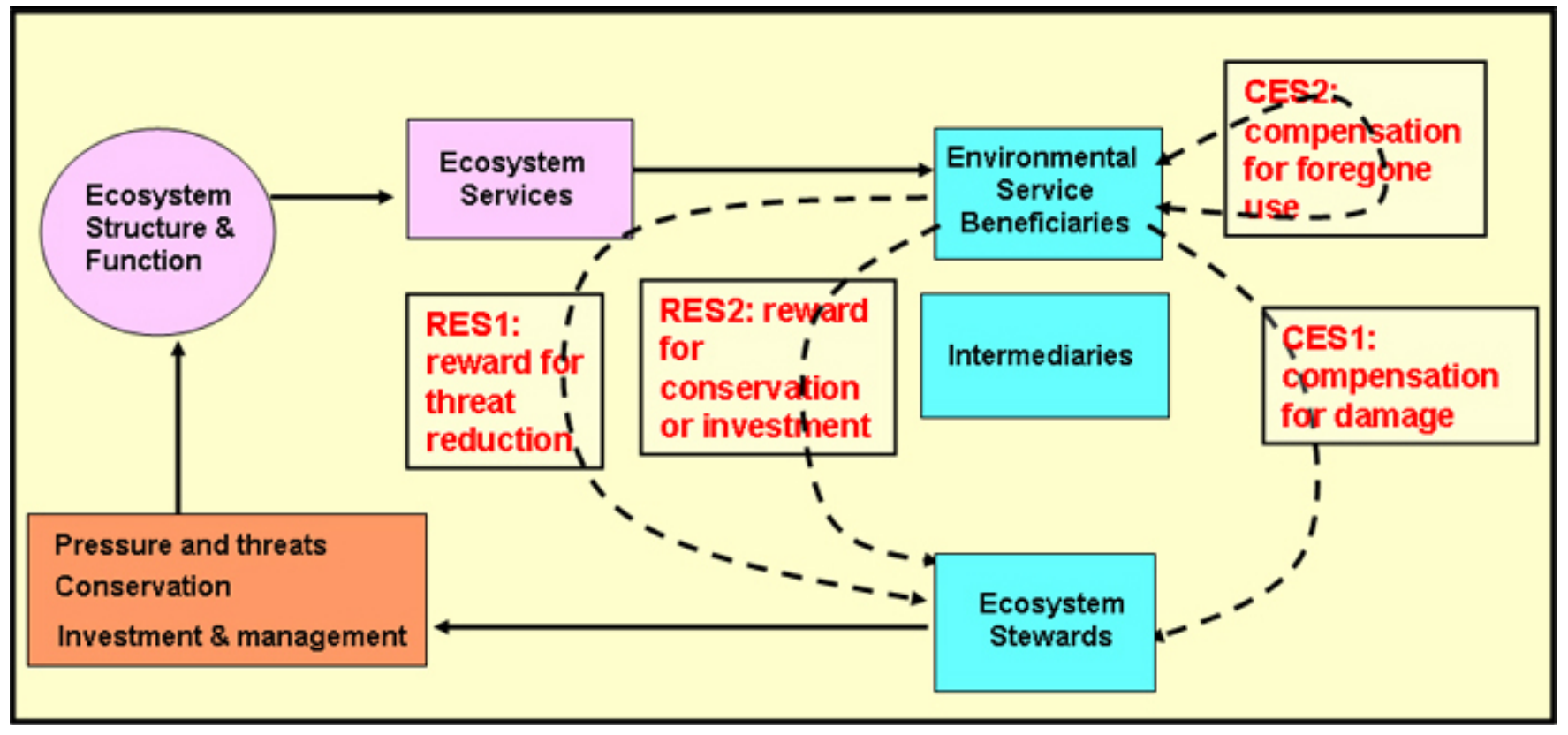

provisioning goods? Are conditional property rights, public services, or extension services explicit or implicit components of the contract or agreement?

- What market-based instruments are used? Market-based instruments are tangible pieces of evidence of environmental services that are issued or certified by some public or private authority and backed by the reputation or legal sanction of that authority. An example of a market-based instrument is the certified emission reduction (CER) that is backed by the Executive Board of the Clean Development Mechanism and certified by reputable private firms.

- Temporal pattern of payment. Is the payment a recurrent payment to offset the opportunity costs of lower returns or a lump sum that is assumed to facilitate ecosystem stewards making the investments necessary to surpass some type of threshold?

\section{CONCLUSIONS}

Previous sections of this paper reviewed the concepts and provided an overview of recent historical development of conservation and environmental policy across the developing world. Conservation organizations have become increasingly interested in the possibility of using compensation and rewards for environmental services to make more efficient use of available funds and for sustaining conservation outcomes. At the same time, the policy, regulatory, and business environments within developing countries are generally becoming more conducive to CRES mechanisms.

The situation unfolding in the developing world is part of a global trend toward more flexible, marketoriented, and multi-stakeholder environmental policy. As governments become less involved in the strict enforcement of hard environmental regulations, non-governmental organizations, international organizations, and civil society organizations are becoming more involved in exerting pressure on companies to adopt good business practices toward the environment. Among the countries of Europe 
and North America, the portfolio of environmental policy instruments varies considerably from country to country, with regulations still forming the main structure of environmental management. We should similarly expect that systems of compensation and reward for environmental services will vary across the developing world. In the developing world, there are even more disparate perceptions of the potential role and function of CRES mechanisms.

Responses to this article can be read online at: http://www.ecologyandsociety.org/voll4/iss2/art26/ responses/

\section{Acknowledgments:}

The ideas presented here have gradually matured in discussions with many of the participants at the Regional Workshops and the final writeshop, and authors of other issue papers. We also acknowledge the generous financial and intellectual support of the International Development Research Centre, the International Fund for Agricultural Development, the European Union, and our respective home institutions. The views expressed do not necessarily reflect those of the funding agencies.

\section{LITERATURE CITED}

Arifin, B., B.Swallow, Suyanto, and R. Coe. 2008. A conjoint analysis of farmer preferences for social forestry contracts in the Sumber Jaya watershed, Indonesia. World Agroforestry Centre Working Paper. World Agroforestry Centre, Nairobi, Kenya.

Callicott, J. B. 1991. The wilderness idea revisited: the sustainable development alternative. The Environmental Professional 13:235-247.

Chape, S., L. Fish, P. Fox, and M. Spalding. 2003. United Nations list of protected areas. IUCN and UNEP, Gland, Switzerland and Cambridge, UK.

Crocker, T.D. 1966. The structuring of atmospheric pollution control systems. Pages 61-68 in $\mathrm{H}$. Wolozin, editor. The economics of air pollution. W. W. Norton \& Co., New York, New York, USA.
Di Leva, C. 2002. The conservation of nature and natural resources through legal and market-based instruments. Reciel 11(1):84-95.

Earthwatch Institute, IUCN, WBCSD, and WRI. 2006. Ecosystem challenges and business implications. Earthwatch Institute, World Resources Institute, WBCSD and World Conservation Union, London, UK and Gland, Switzerland.

Ferraro, P., and A. Kiss. 2002. Direct payments to conserve biodiversity. Science 298:1718-1719.

Fay, C., and G. Michon. 2005. Readressing forestry hegemony when a forestry regulatory framework is best replaced by an agrarian one. Forests, Trees and Livelihoods 15(2):193-209.

Hamilton, K., R. Bayon, G. Turner, and D. Higgins. 2007. State of the voluntary carbon markets 2007: picking up steam. The Ecosystem Marketplace and New Carbon Finance, Washington, D.C., USA and London, UK.

Jordan, A., R. K. W. Wurzel, and A. Zito. 2005. The rise of "new" policy instruments in comparative perspective: has governance eclipsed government? Political Studies 53(3):477-496.

Knight, R. L. 1996. Aldo Leopold, the land ethic, and ecosystem management. The Journal of Wildlife Management 60(3):471-474.

McKay, J., and H. Bjornlund. 2001. Recent Australian market mechanisms as a component of an environmental policy that can make choices between sustainability and social justice. Social Justice Research 14(4):387-403.

Millennium Ecosystem Assessment. 2005. Ecosystems and human well-being: synthesis report. Island Press, Washington, D.C., USA.

Oates, J. F. 1999. Myth and reality in the rain forest: how conservation strategies are failing in West Africa. University of California Press, Berkeley, California, USA.

Ochieng, B., B. Otiende, and R. Rumley. 2007. African regional workshop on compensation for ecosystem services (CES). 22-24 May 2006, Nairobi, Kenya. ICRAF Working Paper No. 35. World Agroforestry Centre, Nairobi, Kenya. 
Ostrom, E. 2005. Understanding institutional diversity. Princeton University Press, New Haven, Connecticut, USA.

Pagiola, S., J. Bishop, and N. Landell-Mills. 2002. Selling forest environmental services, market-based mechanisms for conservation and development. Earthscan, London, UK.

Pagiola, S., A. Arcenas, and G. Platais. 2004. Can payments for environmental services help reduce poverty? An exploration of the issues and the evidence to date from Latin America. World Development 33(2):237-253.

Poats, S. V. 2007. Report on the Latin American regional workshop on compensation for environmental services and poverty alleviation in Latin America. 26-28 April 2006, Quito, Ecuador. ICRAF Working Paper No. 33. World Agroforestry Centre, Nairobi, Kenya.

Robertson, N., and S. Wunder. 2005. Fresh tracks in the forest: assessing incipient payments for environmental services initiatives in Bolivia. Center for International Forestry Research (CIFOR), Bogor, Indonesia.

Rosa, H., S. Kandel, and L. Dimas. 2004. Compensation for environmental services and rural communities: lessons from the Americas. International Forestry Review 6(2):187-194.

Stavins, R. N., 2002. Lessons from the American experiment with market-based environmental policies. Faculty Research Working Paper Series RWP01-032. John F. Kennedy School of Government, Harvard University, Cambridge, Massachusetts, USA.

Tomich, T. P., D. E. Thomas, and M. van Noorwijk, editors. 2004. Environmental services and land use change: bridging the gap between policy and research in Southeast Asia. Elsevier Science. Also published as a special issue of Agriculture, Ecosystems and Environment 104 (1):1-244.

Wells, M., S. Guggenheim, A. Khan, W. Wardojo, and P. Jepson. 1999. Investing in biodiversity: a review of Indonesia's integrated conservation and development projects. The World Bank, Washington, D.C., USA.
Wikimedia Foundation. 2009. Wikipedia, the free encylopedia. Wikimedia Foundation, San Francisco, California, USA. [online] URL: http://en.wikipedia. org/wiki/Compensation.

Woodward, R. 2005. Markets for the environment. Choices: the Magazine of Food, Farm and Resource Issues 20(1):49-51.

Wunder, S. 2005. Payments for environmental services: some nuts and bolts. CIFOR Occasional Paper No. 42. Centre for International Forestry Research, Bogor, Indonesia. 